\title{
Anatomia da alma entre verdade e conhecimento
}

Paulo José Carvalho da Silva

O homem moderno considerava-se perdido num mundo de ilusão e na multiplicidade de objetos, à procura de uma nova orientação. Este artigo objetiva analisar propostas de conhecimento sobre a alma e as escolhas metodológicas da primeira modernidade. Foca-se a analogia da anatomia da alma enquanto método de busca do conhecimento daquilo que o Eu ignora, mas que o causa a despeito de si mesmo.

Palavras-chave: Conhecimento, verdade, anatomia da alma 
Ao longo de seu ensino, Lacan enfatiza que, por causa do inconsciente, o ser humano vive, no limite, um radical desconhecimento de si mesmo. Dito de outro modo, a psicanálise mostra que não há total conhecimento de si. Por essa mesma razão, recomenda-se para aquele que se pergunta sobre seu sofrimento, que fale sobre isso na presença do analista. Vale notar que, em sua argumentação sobre esse abismo entre saber e verdade, Lacan retoma não apenas Freud e a literatura psicanalítica ou a filosofia moderna, cujo grande expoente francês teria sido Descartes, mas também o padre latino Agostinho (354-430), tanto em Posição do inconsciente (1964), como em Ciência e verdade (1966).

Emmanuel Bermon (2001) explica que, para Agostinho, a alma conhece a si mesma na medida em que se indaga sobre si, isto é, na medida em que se ignora. Segundo as Confissões, no mais íntimo do espírito humano está uma forma que se apreende em si, mas que não advém de si. ${ }^{1}$ Mesmo porque a palavra interior, empregada por Agostinho em suas Confissões, é um comparativo em latim, o que, num certo sentido, nos permite afirmar que ela implica sempre uma referência a algo exterior.

$\mathrm{Na}$ Idade Moderna, produziu-se variados discursos sobre o conhecimento de si, influenciados por Agostinho, entre outras referências filosófico-teológicas, que insistem na superação de sua impossibilidade mais radical. A atenção ao pathos mais íntimo permanece um ideal, oposto ao gozo do nada querer saber sobre si. Este artigo objetiva analisar diferentes gêneros de advertências sobre a importância ou propostas de conhecimento sobre a alma e as escolhas metodológicas compartilhadas por autores da primeira modernidade.

1. É o que Bermon (2001), na verdade, retomando uma expressão de Husserl, aponta ser a orientação transcendental do Cogito agostiniano. Para Agostinho, a alma contém todas as realidades que ela encontra, sem ser contida nelas, à exceção de Deus, considerado a condição última da existência e a alteridade mais interior ao espírito que ele próprio. 


\section{Um jardim de alienados}

No início do Diálogo da lembrança da morte, do frei português Heitor Pinto (1525?-1584?), pai e filho comparam o ser humano às estátuas do jardim: "Vivemos tão esquecidos de nós, e tão estrangeiros do que temos por natureza, que com razão podemos ser comparados a estas pedras insensíveis que, tendo olhos, não veem e orelhas, não ouvem" (Pinto, 1940, vol. II, p. 86).

Nessa perspectiva, conhecer-se envolve aceitar não apenas o lugar de criatura, por excelência o lugar de dependência do desejo do Outro, mas também a condição de desterrado, isto é, de exilado da terra Paterna e perdido num mundo onde impera a multiplicidade de objetos, mas nada é, de fato, o que parece ser, inclusive, o próprio homem. Conforme o pensamento católico da época, os homens são o que há de mais inconstante no mundo. No entanto, acham-se sempre maiores do que são, imaginam-se com raízes, pensam que vão durar para sempre. O que, no entender do célebre pregador jesuíta padre Antônio Vieira (1608-1696), seria ainda pior do que não ver nada. Não ver é privação, ver uma coisa por outra é erro:

Eis aqui porque sempre erra o juízo próprio: eis aqui porque nunca acabamos de nos conhecer. Porque olhamos para nós com os olhos de um mais cego que os cegos, com uns olhos que sempre veem uma coisa por outra, e as pequenas lhes parecem grandes. (Vieira, Sermão da Quarta Dominga do Advento, s.d./ 1676, vol. I, p. 246)

O intelectual da primeira modernidade era solitário; ele se retirava em seu gabinete de trabalho, com seus livros, globos, mapas e pensamentos. Ele desconfiava de todos e das reações das autoridades religiosas. Ele interessava-se cada vez mais pela própria imagem. Ao mesmo tempo em que o homem europeu partiu em busca do saber universal e conquistou novas terras, ele também se sentia mais responsável pelo seu sofrimento.

Jean Rouhou (2002) pensa que a crise dos fundamentos e das estruturas do pensamento medieval levou o homem moderno a se assumir como indivíduo e a se interrogar sobre si mesmo, refugiando-se em seu foro interior. Entretanto, não se pode falar ainda de um individualismo soberbo. Tratava-se de modelar um eu a partir de sua posição em relação à igreja, à linhagem, à comunidade, à corte e, mais globalmente, enquanto criatura de Deus.

De qualquer forma, a própria religiosidade tornou-se mais intimista, centrada no interesse pela interioridade e na devoção interior. Tanto os reformados como os católicos participaram desse crescente interesse pelos afetos e pela individualidade, o que teria influenciado suas técnicas de exame de si e seus métodos de conhecimento da alma. 
Ute Mennecke-Haustein (1989) aponta que o tema do cognitio sui, amplamente explorado por Martinho Lutero (1483-1546), era um desdobramento moderno de um motivo absolutamente central da mística medieval do sofrimento: na dor, as pessoas são confrontadas com seus limites e sua condição de dependência do outro. De acordo com Olivier Millet (1995), para João Calvino (1509-1564), a vida espiritual é um combate interior, que implica a manifestação de todos os movimentos da alma, mesmo os mais desordenados. Essa manifestação é realizada com o respaldo da meditação dos salmos, por meio da oração veemente, quase que num balbuciar, em busca da expressão mais simples, pura e subjetiva do pathos.

Inácio de Loyola (1491-1556), sem romper com a linguagem do catolicismo medieval, desenvolveu um programa de introspecção espiritual, em muitos aspectos até mesmo mais sensível à subjetividade do que a disciplina calvinista. Para Loyola, o exame interior era prática central na definição de sua própria espiritualidade. Pierre-Antoine Fabre (Loyola, 2007) enfatiza, inclusive, que a atenção às moções interiores, além de fundamental no próprio tornar-se jesuíta, modelava decisões sobre como operar na realidade a sua volta e como conduzir a própria Companhia de Jesus, sendo, portanto, substrato para ações sociais e políticas.

A prática dos célebres Exercícios espirituais exige, em analogia com os exercícios físicos, um trabalho. Esse trabalho inclui o exame das moções interiores, ou seja, o reconhecimento dos movimentos sentidos na alma. É claro que o diretor espiritual orienta e mesmo dirige esse trabalho, mas ele não pode ser realizado sem que o praticante o deseje.

$\mathrm{Na}$ interpretação de Michel de Certeau (1973), a maneira de proceder proposta por Loyola nos Exercícios pressupõe um desejante em busca de uma decisão a tomar e visa a lhe dar o meio de nomear esse desejo. Para corresponder ao desejo divino, a única alternativa é articular o próprio desejo nos termos limitados e provisórios de uma decisão. Se toda a instauração de uma ordem se inaugura a partir da vontade, será necessário exumar o desejo. Novidade no século XVI, essa que era chamada de theologia affectus tinha por princípio a inserção do affectus na ordem discursiva. O logos se constrói sobre um querer fundamental que dava força e impulso à tarefa de reorganizar a vida.

O conhecimento de si era também um recurso para relacionar-se melhor com o outro, uma preocupação presente nas orientações oficiais dos seguidores de Loyola. Por exemplo, num manual de consolação do jesuíta Gaspard Loarte (1498-1578), especificamente sobre a dificuldade de se conviver longamente com alguém de caráter diferente ou supostamente incompatível, ele recomenda examinar se as desavenças não são provenientes das diferenças de natureza, humor e compleição ou tentação do diabo. Eliminada esta última hipótese, é preciso pro- 
curar esquecer os defeitos do outro e concentrar-se nas boas qualidades da alma do companheiro. Mas, sobretudo, ao fazer o exame de si mesmo será possível tomar conhecimento dos seus próprios defeitos e imperfeições, relativizando, assim, o que incomoda tanto no outro: "você encontrará em si mesmo imperfeições e defeitos ainda maiores do que os daqueles que o incomodam" (Loarte, 1588, p. 175v-176; tradução nossa).

Com a difusão e a renovação da espiritualidade inaciana, o conhecimento de si firma-se como um ideal. Conhecer-se serve ao exercício espiritual e é um requisito para a saúde da alma e para a boa atuação no mundo. Logo, torna-se também assunto de cartas, reflexões diversas e, sobretudo, de sermões.

Os discursos morais do padre Antonio Vieira, chamados de As cinco pedras da funda de Davi em cinco discursos morais, de 1676, tornaram-se uma referência para os pregadores brasileiros (Massimi, 2005). Neles, Vieira afirma que as ações humanas dependem da imagem que o indivíduo tem de si mesmo: "neste mundo racional do homem, o primeiro móbil de todas as nossas ações é o conhecimento de nós mesmos" (...) "O conhecimento de si mesmo, e o conceito que cada um faz de si, é uma força poderosa sobre as próprias ações” (Vieira, 1676, vol. V, p. 607).

Entretanto, no já citado Sermão da Quarta Dominga do Advento, Vieira sentencia: "Nenhuma coisa trazemos os homens mais esquecida e desconhecida, nenhuma trazemos mais detrás de nós que a nós mesmos" (s.d./1951, op. cit., vol. I, p. 247). Segundo o pregador, é preciso voltar os olhos sempre absortos em coisas exteriores, para o interior. Claro que se tratava de um remédio contra a vanglória, deformadora dos conceitos de si, que atinge particularmente os supostos senhores ilustres, poderosos, gentis-homens, sábios e valentes. Esse exame deveria contemplar as intenções, os pensamentos, as palavras e as ações e obras, em analogia ao que externamente seriam os olhos, os cabelos, a boca e as mãos. Isso permitiria traçar um retrato interior, aliás, o verdadeiro:

Vêde se diz esse retrato com o que vós tínheis formado de vós mesmo no vosso pensamento; vêde bem, e considerae muito devagar n'esse espelho, o rosto e as feições interiores da vossa alma; vêde bem esses olhos, que são as vossas intenções; esses cabellos, que são vossos pensamentos; essa bocca, que são vossas palavras; essas mãos, que são as vossas acções e vossas obras; vêde bem se diz essa imagem com a que tendes na vossa idéa; vêde se se parece o que vedes com o que imagináveis; vede se vos conheceis; vêde se sois esse, ou outro: Tu qui es? (Vieira, s.d./1951, vol. I, p. 248-249) 


\section{Dissecar o próprio peito}

Uma imagem muito difundida no período recomendava entrar no próprio coração para examinar desejos, pensamentos, afetos. O que significava travar contato com a unidade mais íntima e misteriosa do ser, porque o coração era considerado o centro da própria pessoa. Scott Manning Stevens (1997) afirma que apesar do crescimento dos estudos anatômicos mostrando, mesmo que timidamente, a função do cérebro para a afetividade e o pensamento, a Igreja do século XVII teria insistido na escolha do coração como centro da pessoa. Ele lembra que no início do século as categorias descritivas do corpo não estavam definidas rigidamente, o que teria permitido ao grande teólogo e poeta metafísico John Donne (1572-1631), por exemplo, referir-se a um "coração pensante" e ao personagem Próspero, de A tempestade de William Shakespeare (1564-1616), descrever sua "mente batente". Stevens defende que os teólogos da primeira modernidade, longe de desprezar os avanços da ciência, teriam apostado na eficiência do simbolismo do coração, tanto do sagrado coração de Cristo, transplantável e mais facilmente representável do que o cérebro, como do coração como sede do que anima cada ser humano. O coração, cuja significação permanece difícil de ser definida, representa a junção do mundo físico e do mundo espiritual.

Birgit Stolt (2000) explica que, no texto de Lutero, o termo coração, Herz em alemão, não traduz apenas o latim Cor, mas também Anima, Intellectum, Voluntatem, Affectum. Na direta influência de Agostinho, Lutero retoma a antropologia bíblica e afirma ser o coração o centro da personalidade humana, no limite, apenas conhecido por Deus. O coração é o mais íntimo do homem, a sede das potências espirituais, da compreensão, do sentimento, da vontade, da memória.

Globalmente, conforme fontes ibéricas e brasileiras dos séculos XVII e XVIII, o conhecimento de si incluía-se no que se pode chamar de exercícios espirituais, ou seja, estava, via de regra, condicionado a uma preocupação propriamente religiosa, mas, de qualquer forma, consistia num olhar para si mesmo, numa atenção especial ao que se passa na alma, muitas vezes, em oposição ao olhar e à apreciação do mundo externo. A bem da verdade, mais do que uma oposição, há um movimento de aplicação dos critérios e procedimentos que eram utilizados na observação da realidade circundante para a esfera íntima da alma, dos afetos e desejos. Por exemplo, em uma carta a um historiador, de outubro de 1671, o alentejano frei Antonio das Chagas (1631-1682), recomenda que esse empregue o seu tempo e a sua inteligência não tanto no exame da história, da geografia, da economia e da cultura, mas da própria alma:

Oh! Se V.S. pusera e empregara em examinar a sua consciência e a sua vaidade o tempo que gastou em examinar os mapas, descrever as terras, considerar 
os mares, as gentes e os costumes, as guerras e os encontros, as fortunas e os infortúnios, que são corpo desta história, que diferente fora o fruto que achara na alma! Se as anatomias que V.S. faz dos sujeitos e dos negócios, se a balança em que pesa os perigos e os interesses, se a observação com que olha estes e aqueles tratos, a fizera V.S. de si mesmo e olhara bem para si, que certo fôra medrar V.S. mais no conhecimento próprio, que as suas prendas no alheio! (Chagas, 1671, p. 23)

Essa anatomia de si, como se refere frei Antonio das Chagas, é o equivalente moderno do que viria a ser ulteriormente a análise da alma, isto é, a decomposição nas menores partes para poder compreendê-la de maneira precisa e minuciosa. De modo geral, a expressão "fazer anatomia de algo" é uma analogia com a dissecção anatômica do corpo que designa operações de conhecimento de outros objetos. Rafael Mandressi (2003) explica que, dentro de uma cultura mais ampla em torno do desenvolvimento dos estudos anatômicos do Renascimento, essa analogia significa não apenas examinar a fundo, mas também revelar, trazer à luz a verdadeira natureza das coisas escondidas e secretas, ir além da superfície imediatamente visível. Em especial, quando se trata de uma anatomia da alma, há toda uma investigação detalhada de sua estrutura, de suas regiões, componentes e, sobretudo, estados e movimentos. ${ }^{2}$

Contudo, essa análise da alma funcionava como uma espécie de suplência onde a voga anatômica tende a fracassar. O conhecimento de si não pode se restringir à observação dos órgãos internos ou mesmo à atenção ao que se passa dentro da pele. David Hillman (1997) lembra que na literatura da primeira modernidade há numerosas menções ao interior do corpo humano, como coração, fígado, estômago, útero, intestinos, sangue ou as entranhas de modo geral, indicando a interioridade do humano e mesmo o caráter moral ou a experiência psicológica, por vezes não manifesta pelas expressões visíveis externamente. Entretanto, ele defende que, por exemplo, nas peças de Shakespeare, a subjetividade, apesar de indissociável da visceralidade, está longe de ser reduzida ao interior do corpo. Para Shakespeare, como para John Donne, Michel de Montaigne e muitos outros autores do período, não há conhecimento preciso sobre o humano a ser encontrado dentro do corpo, exceto o confrontar-se com a realidade da dúvida, da enfermidade e da morte.

2. A analogia parece ter tido enorme sucesso na Europa do período, como atesta a longa lista de títulos dos quais Mandressi ressalta alguns, inclusive, o célebre Anatomia da melancolia (1621) de Robert Burton, no qual o autor propõe uma dissecção médica, filosófica e histórica da melancolia, em suas partes, causas, sintomas, prognósticos e possibilidades de cura. 
As variantes "anatomia do coração" ou "anatomia das paixões" também designam o conhecimento de si. Como analisa Mandressi (2003) o significado é sempre o mesmo: investigar além da face visível de um comportamento, revelar os pensamentos e os desejos muitas vezes dissimulados, identificar a verdadeira natureza dos afetos. É essa operação que aparece em muitos escritos do século XVII que, de alguma forma, abordam a questão das paixões e a importância do conhecimento delas.

O jesuíta francês Etienne Binet (1569-1639), em seu Consolation et réjouissance, já tratado nesta seção (vol. 13, n. 1, p. 116-127. mar.2010), recomenda uma anatomia da melancolia com o escopo de questionar suas causas e, com isso, superar tal condição, compreendendo a origem dos movimentos de sua alma e tornando-se senhor de seus próprios afetos: "Se fizer uma anatomia de sua melancolia, rirá do que atualmente lima seu coração. Pois, seja sincero, o que o faz tão triste?" (Binet, 1627, p. 101, trad. nossa).

Robert Burton (1577-1640) escreve o próprio Anatomia da melancolia a partir de um exame de si mesmo, tomando-o como o remédio decisivo contra a desordem da imaginação que implica o mal melancólico. Esse conhecimento de si consiste, no fundo, no reconhecimento das próprias representações e fantasias sobre si e o mundo. E, como bem salienta Claire Crignon-De Oliveira (2006), Burton beira sempre o risco maior de se empreender esse trabalho na solidão, isto é, a possibilidade de ser tragado pela própria imaginação, uma vez que essa é, ao mesmo tempo, uma força criativa e a antecâmara da loucura. Afinal, que tipo de anatomista é capaz de dissecar o próprio peito?

Em outras palavras, sem a ajuda do outro, tal conhecimento pode ser enviesado pelas imagens de si, deformadas pelos caprichos da vaidade e desordens da paixão, num jogo de espelhos, que mesmo voltados para o interior, refletem infinitamente apenas o olhar.

Em suma, o conhecimento de si, que culmina na alteridade, era um ideal do homem moderno, esse estrangeiro de si mesmo, desterrado, descentrado e sempre a procura de uma palavra que o definisse. A metáfora da anatomia da alma ou dissecção do coração ajudou a integrar esse ideal no campo do saber, perpetuando-o no âmbito da longa tradição da medicina da alma.

Não é sem razão que Freud, aquele que nunca deixou de dissecar os próprios sonhos, nomeia uma das Novas conferências introdutórias à psicanálise (1933), justamente aquela que descreve o aparelho psíquico, de Die Zerlegung der psychischen Persönlichkeit, título que Paulo César de Souza traduz como "A dissecção da personalidade psíquica", explicando que o verbo cognato zerlegen significa decompor, desmontar, desintegrar, analisar (Freud, 1933, p. 192). Em sua apresentação da anatomia psicanalítica da alma, Freud lembra que a própria investigação que deu origem à psicanálise tinha como objeto o sintoma, aquilo que 
é mais alheio ao Eu. Diz isso para reiterar que o sintoma vem do recalcado, que é, para o Eu, terra estrangeira interior, assim como a realidade é terra estrangeira exterior.

\section{Referências}

Agostinho. Les Confessions. Edição bilingue latim francês de E. Tréhorel e G. Bouissou. Paris: Institut d'Études Augustiniennes, 1998.

Bermon, E. Le cogito dans la pensée de Saint Augustin. Paris: J. Vrin, 2001. BINET, E. (1627). Consolation et réjouissance pour les malades et personnes affligés en forme de dialogue. Texte presenté par Claude Louis-Combet. Grenoble: Jérôme Millon, 1995.

BURTON, R. The anatomy of melancholy: what it is, with all the kinds, causes, symptomes, prognostickes and severall cures of it (...). Oxford: Cripps, 1638.

Certeau, M. de. L'espace du désir ou Le "fondement" des Exercices Spirituels. Christus, t. 20, n. 77, p. 118-128, 1973.

Chagas, A. das (1671). Cartas Espirituais. Organizado por M. Rodrigues Lapa. Lisboa: Livraria Sá da Costa, 1939.

Crignon-de Oliveira, C. De la mélancolie à l'enthousiasme. Robert Burton (15771640) et Anthony Ashley Cooper, comte de Shaftesbury (1671-1713). Paris: Honoré Champion Éditeur, 2006.

FReUd, S. (1933). A dissecção da personalidade psíquica. In: Novas conferências introdutórias à psicanálise. In: Obras completas. Tradução de P. C. de Souza. São Paulo: Companhia das Letras, 2010. v. 18, p. 192-223.

Hillman, D. Visceral knowledge. Shakespeare, Skepticism, and the interior of the Early Modern Body. In: Hillman, D.; Mazzio, C. (Orgs.). The body in parts: fantasies of corporeality in early modern Europe. New York/London: Routledge, 1997. p. 81-105 LaCan, J. Position de l'inconscient. In: Écrits. Paris: Seuil, 1966. p. 829-50.

. La science et la vérité. In: Écrits. Paris: Seuil, 1966. p. 855-77.

LoARTe, G. La consolation des affligez: ou il est traicté des fruicts et remedes des tribulations. (...) Mis en Fraçois par Pierre Frison Chaneine de l'Eglise nostre Dame de Reims. Paris: Iean Corbon, 1588.

Loyola, I. Journal des motions intérieures. Éditions critiques et nouvelle traduction des manuscrits autographes par Pierre-Antoine Fabre. Bruxelles: Éditions Lessius, 2007. 
MANDRESSI, R. Le regard de l'anatomiste. Dissections et invention du corps en Occident. Paris: Seuil, 2003.

Massimi, M. Palavras, almas e corpos no Brasil colonial. São Paulo: Loyola, 2005. Mennecke-Haustein, U. Luthers Trostbriefe. Gütersloh: Gütersloher Verlagshaus G. Mohn,1989.

MilLEt, O. La "leçon des émotions": l'expression des passions et sa légitimité dans le Commentaire de Calvin sur le psaumes. In: Yon, B. (Org.). La peinture des passions de la Renaissance à l'Age classique: actes du colloque international: Saint-Etienne, 10, 11, 12 avril 1991. Saint-Etienne: Université de Saint-Etienne, 1995.

Pinto, H. Imagem da vida cristã. Quatro volumes. Lisboa: Livraria Sá da Costa, 1940.

Roноu, J. Le XVIIe siècle, une révolution de la condition humaine. Paris: Seuil, 2002. SiLva, P.J.C. A insubmissão contra o gozo do pathos ou como desarmar a resistência do melancólico. Revista Latinoamericana de Psicopatologia Fundamental, São Paulo, v. XII, n. 1, p. 116-27, mar.2010.

Stevens, S. M. Sacred heart and secular brain. In: Hillman, D.; Mazzio, C. (Orgs.). The body in parts: fantasies of corporeality in early modern Europe. New York/London: Routledge, 1997. p. 263-82.

Stolt, B. Martin Luthers Rhetorik des Herzens. Tübingen: Mohr Siebeck, 2000. VIEIRA, A. (1676). Sermões. Porto: Lello e Irmão, 1951. 15 vs.

\section{Resumos}

(Anatomy of the soul between truth and knowledge)

Modern man considered himself lost in a world of illusion and in a multiplicity of objects, in search of a new guide. This article analyzes proposals for knowledge about the soul and the choice of methodology in the first modernity. The focus is on an analogy of the anatomy of the soul as a method for searching for knowledge about what the ego does not know, but which causes it, despite itself.

Key words: Knowledge, truth, anatomy of the soul

(L'anatomie de l'âme entre science et vérité)

L'homme moderne se supposait perdu dans un monde d'illusion et dans la multiplicité d'objets, à la recherche d'une nouvelle orientation. Cet article a pour but d'analyser des propositions de connaissance de l'âme et les choix méthodologiques de la première modernité. L'accent est mis sur l'analogie de l'anatomie de l'âme en tant 
que méthode de recherche sur ce que le Moi ignore et pourtant le cause malgré lui. Mots clés: Connaissance, vérité, anatomie de l'âme

\section{(Anatomía del alma entre verdad y conocimiento)}

El hombre moderno se consideraba perdido en un mundo de ilusión y en la multiplicidad de objetos, en búsqueda de una nueva dirección. Este artículo tiene como objetivo discutir propuestas para el conocimiento acerca del alma y las opciones metodológicas de la primera modernidad. Se centra en la analogía de la anatomía del alma como un método de buscar el conocimiento de lo que yo no lo sé, pero que la causa a pesar de sí mismo.

Palabras clave: Conocimiento, verdad, anatomía del alma

Citação/Citation: SILVA, P.J.C DA. Anatomia da alma entre verdade e conhecimento. Revista Latinoamericana de Psicopatologia Fundamental, São Paulo, v. 14, n. 1, p. 134-144, mar.2011.

Editor do artigo/Editor: Prof. Dr. Paulo José Carvalho da Silva

Recebido/Received: 15.12 .2010 / 12.15.2010 Aceito/Accepted: 20.1.2011 / 1.20.2011

Copyright: (C) 2009 Associação Universitária de Pesquisa em Psicopatologia Fundamental/ University Association for Research in Fundamental Psychopathology. Este é um artigo de livre acesso, que permite uso irrestrito, distribuição e reprodução em qualquer meio, desde que o autor e a fonte sejam citados/This is an open-access article, which permits unrestricted use, distribution, and reproduction in any medium, provided the original author and source are credited.

Financiamento/Funding: $\mathrm{O}$ autor declara não ter sido financiado ou apoiado/The author has no support or funding to report.

Conflito de interesses/Conflict of interest: $\mathrm{O}$ autor declara que não há conflito de interesses/The author declares that has no conflict of interest.

\section{Paulo José Carvalho da Silva}

Psicólogo, psicanalista, mestre em História da Ciência pela Pontifícia Universidade Católica de São Paulo - PUC-SP; doutor em Psicologia pela Universidade de São Paulo - USP (São Paulo, SP, Brasil); membro da Associação Universitária de Pesquisa em Psicopatologia Fundamental (São Paulo, SP, Brasil); bolsista de produtividade em pesquisa do Conselho Nacional de Desenvolvimento Científico e Tecnológico - CNPq (Brasília, DF, Brasil)

Rua Cajaíba, 15 05025-000 São Paulo, SP, Brasil

Fone: (11) 9248-9202

e-mail: paulojcs@hotmail.com 